\title{
T-Cell Activation
}

National Cancer Institute

\section{Source}

National Cancer Institute. T-Cell Activation. NCI Thesaurus. Code C19053.

T-Cell Activation involves stimulation of T lymphocytes by receptor interaction with mitogens or cell surface-displayed antigens resulting in biosynthesis of lymphokines, cell proliferation, cell differentiation, and maturation to support immune activity. 